\title{
THE MAPPING OF INDUSTRIAL EFFLUENT ON COASTAL SEDIMENTS USING EDX
}

\author{
MICHAEL A. GREGORY ${ }^{\mathrm{a}, *}$, TIMOTHY P. MCCLURG ${ }^{\mathrm{b}}$ \\ and CHRISTOPHER J. BROUCKAERT ${ }^{\mathrm{c}}$
}

${ }^{a}$ Electron Microscope Unit, University of Durban-Westville, Private Bag X54001, Durban 4000, South Africa; ${ }^{b}$ CSIR, Division of Water, Environment and Forestry Technology, Durban; ${ }^{\mathrm{c}}$ Department of Chemical Engineering, University of Natal, Durban

(Received 5 December 2001; In final form 28 March 2002)

\begin{abstract}
Marine pollution monitoring surveys often include the measurement of heavy metals and other trace elements in sediments from multiple stations around marine outfalls. EDX may offer a supplementary, relatively cheap and rapid screening method where 'signature' elements in effluent can be traced on the sea-bed. 'Hot-spots' so identified, may subsequently be examined by more sensitive spectroscopic techniques and trace metals quantified. This paper describes the methodology for EDX evaluation of both effluent and sediments, establishes control criteria and applies these criteria to samples of sediment obtained from near the Huntsman Tioxide and Richards Bay A and B pipelines. Tioxide effluent was rich in Ti and Fe and Richards Bay, A and B pipelines, rich in $\mathrm{Ca}$ and $\mathrm{P}$. Sediments obtained from near the outfalls were screened for these elements using EDX. Excess concentrations (EC) of signature elements in sediments near pipelines were determined by calculating the wt.\% difference of each element in samples from near pipelines with its expected value, based on the measured wt. \% in the coarse fraction, and the correlation established from the pristine control areas. Surfer 16 software was employed to create plots of EC for each element. The resultant contour plots confirmed that EDX offers a rapid means of delimiting the spatial distribution of effluent fallout and identifying the position of signature element 'hot-spots' on the sea-bed.
\end{abstract}

Keywords: EDX; Marine sediments; Pollution; Effluent

\section{INTRODUCTION}

The South African Department of Water Affairs and Forestry applies stringent conditions for the discharge of effluent through deep-sea outfalls. Amongst these is a requirement that environmental impact is closely monitored and that ecological integrity is maintained. A common approach, currently being used in monitoring surveys on the South African east coast [1,2], is to use spectroscopy to measure the concentration of trace metals in sediment samples taken on a wide grid of stations surrounding an outfall [3-6] and to correlate these data to the presence, absence or changes in benthic community structures $[7,8]$. Co-occurrences of chemical

*Corresponding author. Fax: +031-204 4360. E-mail: mgregory@pixie.udw.ac.za 
contamination and aberrant benthic communities are then used to demarcate 'zones of impact' [9].

In this pilot study, we investigate the possibility that EDX could be used as a preliminary and supplementary means of mapping the distribution of elemental contaminants within sediments, and by inference, enabling the recognition of areas where there has been effluent 'fallout'. This information could be useful in validating or calibrating predictive modelling of effluent dispersal patterns [10-12] and in highlighting 'hot-spots' which could then be subjected to more detailed analyses using more sensitive spectroscopic techniques.

\section{EXPERIMENTAL}

All samples for analysis were derived from the CSIR's deep-frozen store of sediments. The specimens were obtained in 1995 during routine monitoring surveys. To serve as controls, 12 samples were selected from two widely separated, pristine areas. Three samples (L-series) were obtained in shallow water, $1.5-2.5 \mathrm{kms}$ from the Lovu River mouth $\left(30^{\circ} 52^{\prime}\right.$ East $/ 30^{\circ} 7.5^{\prime}$ South) and 9 samples (U-series) were obtained in deeper water, $7.5 \mathrm{~km}$ off the coast near Umkomaas (30 $52^{\prime}$ East $/ 30^{\circ} 13.5^{\prime}$ South). Samples of effluent were obtained prior to discharge into the Huntsman Tioxide pipeline off Amamzimtoti $\left(30^{\circ} 54.5^{\prime}\right.$ East $/ 30^{\circ} 3^{\prime}$ South) and the two Richards Bay pipelines known as the A- and B-Lines ( $32^{\circ} 8.5^{\prime}$ East $/ 28^{\circ} 49^{\prime}$ South). Thirty-two samples of sediments were selected from stations within $1 \mathrm{~km}$ of the Huntsman Tioxide pipeline and 11 from within $1 \mathrm{~km}$ of the Richards Bay pipelines.

\section{Preparation of Effluent for EDX Analysis}

Particulate (Tioxide) or flocculant (Richards Bay) material had settled to the bottom of each sample of effluent. This was removed by pipette and centrifuged at $2000 \mathrm{rpm}$ for $2 \mathrm{~min}$. Most of the supernatent was removed and the residue dried on to a graphite disk or a brass stub (to determine $\mathrm{C}$ content).

\section{Sediment Separation Procedures and Preparation of Fractions for EDX Analysis}

Each frozen sample half filled a flip-top, $60 \mathrm{~mL}$ polythene container. The container was warmed, filled with distilled water and the substrate stirred. The container was placed in an ultrasonic bath for $10 \mathrm{~min}$, and the supernatant filtered through a stainless steel, plain weave, $300 \times 500 \mu \mathrm{m}$ mesh, and then through Whatman No. 6 filter paper. This was repeated until an adequate amount of fines had deposited onto the filter paper (3-10 washings depending on the amount of particulate material in the sample). The filter paper was removed from the funnel and dried in a partially enclosed petri-dish at $70^{\circ} \mathrm{C}$.

Approximately $10 \mathrm{~g}$ of the coarse fraction (sands) was placed in a clean $50 \mathrm{~mL}$ plastic vial. To removal all trace of fines, the sands were ultrasonicated in distilled water for $30 \mathrm{~min}(\times 5)$. The clear supernatant was removed and the coarse fraction dried in an oven at $70^{\circ} \mathrm{C}$.

Double sided carbon-tape was affixed to a $2.5 \mathrm{~cm}$ diameter brass stub, and $50 \%$ of the surface pressed into a sample of dried, clean sand. A segment, approximately 
$1 \mathrm{~cm} \times 2 \mathrm{~cm}$, of filter paper containing fines from the same sample was affixed next to the sand. To make the samples conductive for scanning electron microscopy, they were each coated with approximately $20 \mathrm{~nm}$ of carbon using a Polaron carbon evaporator.

\section{Collection of Data}

The standardless analyses of both the fine and coarse fractions were 'forced' to include: $\mathrm{Mg}, \mathrm{Al}, \mathrm{Si}, \mathrm{K}, \mathrm{Ca}, \mathrm{Ti}, \mathrm{Fe}, \mathrm{Hg}, \mathrm{Pb}, \mathrm{Cr}, \mathrm{Ni}, \mathrm{As}, \mathrm{Cd}$, Se, P, Cu, S, Mo and Zn. The inclusion of these elements always gave a $\chi^{2}<2$ indicating good conformity. Carbon and $\mathrm{O}_{2}$ were taken out of the matrix. With an accelerating voltage of $25 \mathrm{kV}$, a working distance of $15 \mathrm{~mm}$, a dead-time of between 25 and $30 \%$ (beam current ranged from 0.418 to $480 \mathrm{nA}$ for fines: $0.315-0.520 \mathrm{nA}$ for sands - measured using a Faraday cage) and a magnification of $\times 22$, five areas of each fine and coarse fraction were examined for 60 s using a Noran 'Voyager' 2100 EDX system interfaced with a Jeol 6100 scanning electron microscope. Each of the five, $60 \mathrm{~s}$ analyses covered an area of approximately $13.25 \mathrm{~mm}^{2}$. The data from the five analyses were averaged and the amount of a particular element in each sample expressed as a weight percentage (wt.\%). During the course of the study, two sets of data were obtained for each grid position - those representing (a) fines (particles $<0.3 \mu \mathrm{m}$ ); (b) coarse (sands and fragments $>0.3 \mu \mathrm{m}$ ). The wt. $\%$ data are expressed as tables, graphs and contour maps. Comparisons between data were made using the Student $t$-test (two samples assuming unequal variance $-p<0.05$ ).

\section{RESULTS}

\section{Effluents}

Huntmsan Tioxide The sample was primarily composed of a white, particulate material. Scanning electron microscopy revealed the sample to be composed of amorphous particles with a diameter of approximately $1 \mu \mathrm{m}$. Spot, EDX analyses revealed these particles to be primarily composed of $\mathrm{Ti}(90 \mathrm{wt} \%$ ). The dried supernatent was rich in $\mathrm{Fe}$ and $\mathrm{Ca}$.

Richards Bay: A-Line The sample was composed of a dark brown amorphous material with a pungent odour of faeces. Analyses revealed the material to be primarily composed of carbon (93 wt.\%). Of the remaining elements, Ca, P, Si, S, Al, Fe and K occurred in small amounts.

Richards Bay: B-Line The sample was composed of a pale-brown amorphous material interspersed with white particles. Less than $50 \mathrm{wt} . \%$ was carbon. The SEM revealed an irregular, homogenous matrix within which were implanted regular flakes approximately $100 \mu \mathrm{m}$ in length, $40 \mu \mathrm{m}$ in width and $5 \mu \mathrm{m}$ in thickness. EDX revealed the flakes to be primarily composed of Ca $(50 \mathrm{wt} . \%)$. The elemental composition of the remaining matrix was $\mathrm{P}(30 \mathrm{wt} . \%)$ with $\mathrm{Si}, \mathrm{S}$ and $\mathrm{F}$ present in small amounts. From the above, the primary signature elements from the Huntsman Tioxide outfall were Ti and Fe and for both Richard Bay outfalls, Ca and P. 


\section{SEDIMENTS}

\section{Samples from Pristine Areas}

Fine Fraction There were no obvious morphological differences in the appearance of filtered fines from grid positions within the $\mathrm{L}$ and $\mathrm{U}$ series of samples. There were, however, differences in the colours of fines from the two areas with those from $\mathrm{L}$ sites appearing pale-grey while $U$ samples had an orange tinge. Of the 19 elements sought by $\mathrm{EDX}$, only $\mathrm{Mg}, \mathrm{Al}, \mathrm{Si}, \mathrm{K}, \mathrm{Ca}$, $\mathrm{Ti}$ and $\mathrm{Fe}$ were present in significant amounts $(>0.5 \mathrm{wt} . \%)$ in at least three of the five analyses per sample from each grid position. Although $\mathrm{P}$ was generally below the threshold for EDX, as an important signature element, the wt.\% were nevertheless reported. The amounts of these elements at each grid position together with the composite means and standard deviations of the means $(S D)$ of each series are shown in Table I. Also shown is the combined 'grand' mean, $S D$, high and low values of each element in all fines from $\mathrm{L}$ and $\mathrm{U}$ areas. Note that with the exception of $\mathrm{Ti}(p=0.08)$, the wt. $\%$ of elements in $\mathrm{L}$ differed to those in $\mathrm{U}$ $(p<0.05)$.

Coarse Fraction The particles in the coarse fraction from the L-series ranged from 0.2 to $0.5 \mathrm{~mm}$ in diameter. The smallest, most uniform particles were at grid position LC. The composition of the coarse fraction of U-series samples varied from 0.2 to $2 \mathrm{~mm}$, the larger particles generally being shell fragments. Grid position U:9 had the smallest most uniform grains, $\mathrm{U}: 7$ and 8 had small grains interspersed with larger particles, while positions $U: 1-6$ has grains of widely ranging sizes with numerous fragments of

TABLE I The weight percent (wt.\%) of elements in the fine fraction of sediments from $\mathrm{L}$ and $\mathrm{U}$ stations together with the composite means and standard deviations of the means $(S D)$ of each element from each site. Also shown is the combined 'grand' mean**, $S D^{* *}$, high** and low** values of each element in all coarse fractions from pristine areas. $p=$ significance of difference between $\mathrm{L}$ and $\mathrm{U}$ data

\begin{tabular}{lllllllll}
\hline Elements & $M g-K$ & $A l-K$ & $S i-K$ & $K-K$ & $C a-K$ & $T i-K$ & $F e-K$ & $P-K$ \\
\hline LA & 1.32 & 18.1 & 49.7 & 5.51 & 3.8 & 1.66 & 16.7 & 0.4 \\
LB & 1.6 & 20.4 & 48.3 & 5.09 & 4.23 & 1.5 & 16.4 & 0.24 \\
LC & 1.44 & 20.9 & 44.8 & 4.77 & 4.25 & 2.34 & 18.7 & 0.33 \\
Mean & 1.5 & 19.8 & 47.6 & 5.1 & 4.1 & 1.8 & 17.3 & 0.3 \\
$S D$ & 0.1 & 1.5 & 2.5 & 0.4 & 0.3 & 0.4 & 1.3 & 0.1 \\
U1 & 2.37 & 7.64 & 26 & 1.82 & 50.9 & 0.71 & 7.33 & 0.69 \\
U2 & 1.13 & 19.8 & 54.2 & 4.88 & 1.57 & 1.45 & 14.7 & 0.22 \\
U3 & 2.18 & 7.12 & 25 & 1.69 & 52.1 & 0.69 & 8.32 & 0.9 \\
U4 & 1.66 & 11.7 & 32.1 & 2.49 & 37.6 & 1.02 & 10.6 & 0.62 \\
U5 & 1.62 & 11.4 & 38.5 & 3.17 & 29.5 & 1.31 & 11.6 & 0.57 \\
U6 & 1.76 & 10.3 & 34.5 & 2.59 & 37.5 & 0.99 & 9.85 & 0.51 \\
U7 & 1.66 & 13.3 & 42.6 & 3.43 & 22.6 & 1.1 & 12.7 & 0.37 \\
U8 & 1.84 & 12.7 & 35.5 & 3.14 & 29.1 & 1.5 & 12.9 & 0.47 \\
U9 & 1.69 & 14.6 & 45.5 & 3.8 & 15.8 & 1.39 & 14.2 & 0.44 \\
Mean & 1.8 & 12.1 & 37.1 & 3.0 & 30.7 & 1.1 & 11.4 & 0.5 \\
$S D$ & 0.4 & 3.8 & 9.3 & 1.0 & 16.2 & 0.3 & 2.5 & 0.2 \\
$p=* *$ & 0.05 & 0.0007 & 0.01 & 0.0005 & 0.001 & 0.08 & 0.0007 & 0.01 \\
Mean** & 1.7 & 14.0 & 39.7 & 3.5 & 24.1 & 1.3 & 12.8 & 0.5 \\
SD** & 0.3 & 4.8 & 9.3 & 1.3 & 18.3 & 0.5 & 3.5 & 0.2 \\
High** & 2.4 & 20.9 & 54.2 & 5.5 & 52.1 & 2.3 & 18.7 & 0.9 \\
Low** & 1.1 & 7.1 & 25.0 & 1.7 & 1.6 & 0.7 & 7.3 & 0.0 \\
\hline & & & & & & & &
\end{tabular}


shell. The wt. $\%$ of elements at each grid position together with the composite means and $S D$ of each series are shown in Table II. Also shown is the combined 'grand' mean, $S D$ high and low values of each element in all 'sands' from pristine areas. Note that with the exception of $\mathrm{Ti}(0.06)$, the wt. $\%$ of elements in $\mathrm{L}$ differed to those in $\mathrm{U}(p<0.05)$.

Correlation of Fine and Coarse Fraction Compositions Of particular interest was the comparative data from the two sample sites. Higher or lower wt. \% values of each element from sand correlated with a similar higher or lower value in corresponding fines (Table III). The measured wt.\% of each element in the fine fraction was plotted against the corresponding value for the coarse fraction. Figures 1 and 2 serve as examples for $\mathrm{Ca}$ and Ti respectively. Although these plots contained a fair amount of scatter, they exhibited reasonably well-defined, consistent relationships between the two sets of weight percentages. In particular, although the data from the two different sites fell into significantly different ranges of values, the wt. $\%$ of elements in their coarse and fine fractions appeared to follow similar, 'natural' relationships. As the underlying physical mechanisms for such correlation are not known, these correlating relationships were simply derived graphically from the plots and are represented by the lines in Figs 1 and 2.

TABLE II The wt. \% of elements in the coarse fraction of sediments from $\mathrm{L}$ and $\mathrm{U}$ stations together with the composite means and $S D$ of each element from each site. Also shown is the combined 'grand' mean**, $S D^{* *}$, high $^{* *}$ and low** values of each element in all fines fractions from pristine areas. $p=$ significance of difference between $\mathrm{L}$ and $\mathrm{U}$ data

\begin{tabular}{lllllllll}
\hline Elements & $M g-K$ & $A l-K$ & $S i-K$ & $K-K$ & $C a-K$ & $T i-K$ & $F e-K$ & $P-K$ \\
\hline LA & 0.35 & 5.14 & 64.1 & 3.06 & 20.5 & 0.31 & 1.96 & 0.54 \\
LB & 0.28 & 3.61 & 66.1 & 1.93 & 21.7 & 0.65 & 1.74 & 0.71 \\
LC & 0.33 & 6.44 & 70.7 & 3.42 & 12.2 & 0.6 & 2.88 & 0.59 \\
Mean & 0.3 & 5.1 & 67.0 & 2.8 & 18.1 & 0.5 & 2.2 & 0.6 \\
$S D$ & 0.0 & 1.4 & 3.4 & 0.8 & 5.2 & 0.2 & 0.6 & 0.1 \\
U1 & 1.1 & 0.65 & 43.3 & 0.42 & 51.6 & 0.15 & 0.93 & 0.32 \\
U2 & 0.71 & 1.09 & 58.9 & 1.7 & 33.2 & 0.19 & 0.56 & 0.36 \\
U3 & 1.35 & 0.95 & 39.3 & 0.39 & 52.4 & 0.04 & 1.38 & 0.44 \\
U4 & 0.8 & 0.8 & 54.3 & 0.6 & 38.3 & 0.4 & 0.6 & 0.8 \\
U5 & 0.37 & 2.0 & 58.2 & 1.6 & 34.1 & 0.3 & 0.8 & 0.6 \\
U6 & 1.07 & 0.86 & 41.3 & 0.71 & 50.8 & 0.12 & 1.22 & 0.56 \\
U7 & 0.97 & 1.12 & 47.9 & 0.43 & 44.9 & 0.61 & 1.15 & 0.56 \\
U8 & 0.79 & 1.13 & 50.2 & 0.73 & 41.8 & 0.07 & 0.94 & 0.46 \\
U9 & 0.87 & 1.79 & 57.6 & 0.52 & 33.7 & 0.16 & 1.47 & 0.32 \\
Mean & 0.9 & 1.1 & 50.1 & 0.8 & 42.3 & 0.2 & 1.0 & 0.5 \\
$S D$ & 0.3 & 0.4 & 7.6 & 0.5 & 8.0 & 0.2 & 0.3 & 0.1 \\
$p=*$ & 0.0002 & 0.04 & 0.0008 & 0.03 & 0.02 & 0.06 & 0.08 & 0.05 \\
Mean** & 0.7 & 2.1 & 54.3 & 1.3 & 36.2 & 0.3 & 1.3 & 0.5 \\
$S D^{* *}$ & 0.4 & 1.9 & 10.1 & 1.1 & 13 & 0.2 & 0.7 & 0.1 \\
High** & 1.4 & 6.4 & 70.7 & 3.4 & 52.2 & 0.7 & 2.9 & 0.8 \\
Low** & 0.3 & 0.7 & 39.3 & 0.4 & 12.2 & 0 & 0.6 & 0.3 \\
\hline
\end{tabular}

TABLE III The average wt.\% of each element in both sands and fines from the L and U series of samples

\begin{tabular}{|c|c|c|c|c|c|c|c|c|c|c|c|c|c|c|c|c|}
\hline & \multicolumn{2}{|c|}{$M g$} & \multicolumn{2}{|c|}{$A l$} & \multicolumn{2}{|c|}{$S i$} & \multicolumn{2}{|c|}{$K$} & \multicolumn{2}{|c|}{$\mathrm{Ca}$} & \multicolumn{2}{|c|}{$T i-K$} & \multicolumn{2}{|c|}{$\mathrm{Fe}$} & \multicolumn{2}{|c|}{$P-K$} \\
\hline & $\mathrm{L}$ & $\mathrm{U}$ & $\mathrm{L}$ & $\mathrm{U}$ & $\mathrm{L}$ & $\mathrm{U}$ & $\mathrm{L}$ & $\mathrm{U}$ & $\mathrm{L}$ & $\mathrm{U}$ & $\mathrm{L}$ & $\mathrm{U}$ & $\mathrm{L}$ & $\mathrm{U}$ & $\mathrm{L}$ & $\mathrm{U}$ \\
\hline Sand & 0.3 & 0.9 & 5.1 & 1.1 & 67 & 50 & 2.8 & 0.8 & 18.1 & 42 & 0.5 & 0.2 & 2.2 & 1 & 0.6 & 0.5 \\
\hline Fine & 1.5 & 1.8 & 19.8 & 12.1 & 48 & 37 & 5.1 & 3 & 4.1 & 31 & 1.8 & 1.1 & 17.3 & 11.4 & 0.3 & 0.5 \\
\hline
\end{tabular}




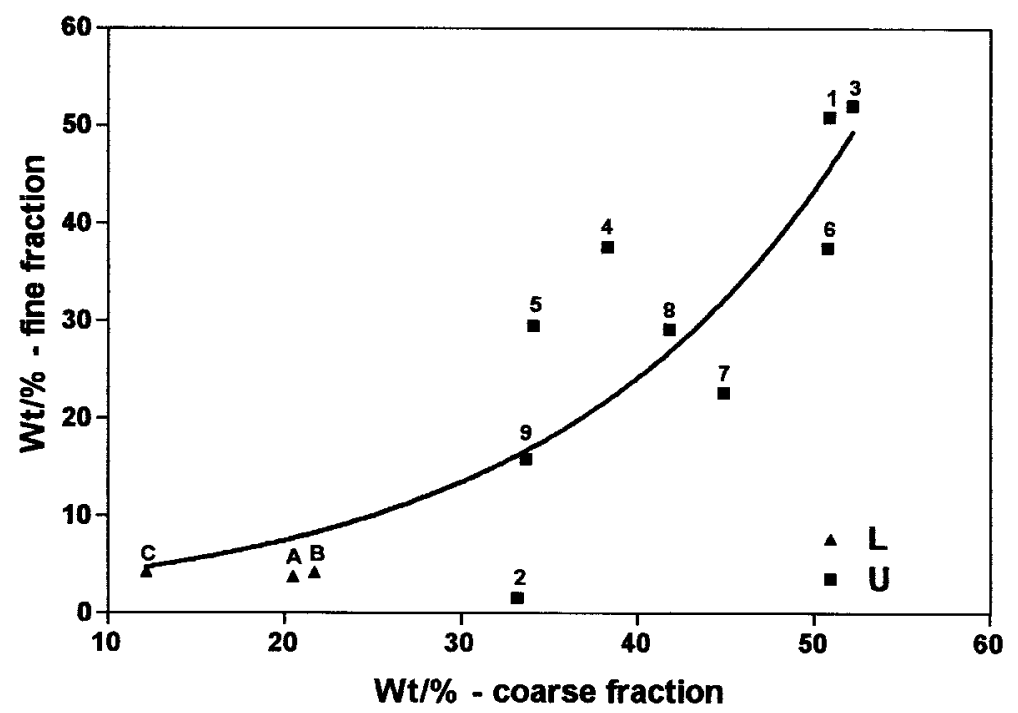

FIGURE 1 Wt.\% of $\mathrm{Ca}$ in the fine and coarse fractions from the $\mathrm{L}$ and $\mathrm{U}$ sites. The line shows the correlation relationship between the Ca contents in the two size fractions.

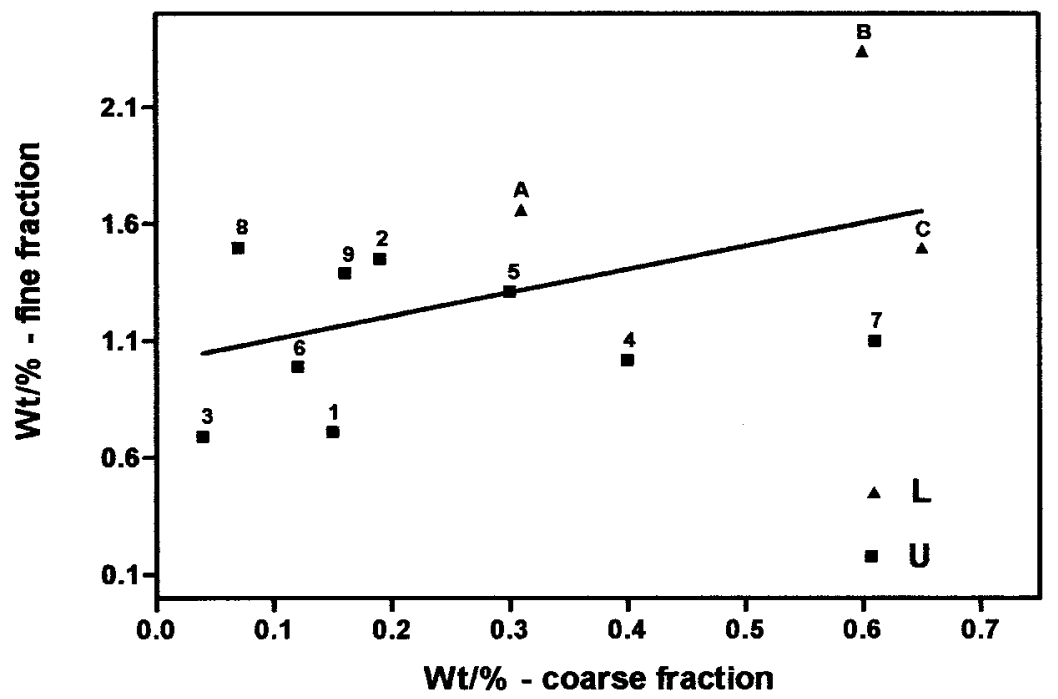

FIGURE $2 \mathrm{Wt} \%$ of $\mathrm{Ti}$ in the fine and coarse fractions from the $\mathrm{L}$ and $\mathrm{U}$ sites. The line shows the correlation relationship between the Ti contents in the two size fractions.

Each line represents the expected wt.\% of a particular element in the fines for any measured wt. \% of the same element in the coarse fraction, in an area that is free of industrial contamination. The scatter of data points about the lines indicates the degree of uncertainty in the correlating relationships. To obtain a quantitative measure of this uncertainty, the residual differences between the measured wt.\% in the fines and the values expected from the measured coarse fraction wt.\% in each sample 
TABLE IV Residual differences, at each sampling point, between the wt.\% of each element in the fine fraction and its expected value based on the wt. $\%$ measured in the coarse fraction. $p^{*}=$ the significance of difference between the $\mathrm{L}$ and $\mathrm{U}$ groups. High** $=$ the highest residual difference for each element - to be used as 'control maxima' of normal range for subsequent contour mapping of elements in sediments from near pipelines

\begin{tabular}{|c|c|c|c|c|c|c|c|c|}
\hline Elements & $M g-K$ & $A l-K$ & $S i-K$ & $K-K$ & $C a-K$ & $T i-K$ & $\mathrm{Fe}-\mathrm{K}$ & $P-K$ \\
\hline LA & -0.11 & -1.39 & 3.22 & 0.48 & -4.06 & 0.34 & 1.60 & -0.08 \\
\hline LB & 0.22 & 2.12 & 0.48 & 0.53 & -4.28 & -0.16 & 2.06 & -0.24 \\
\hline $\mathrm{LC}$ & 0.03 & 0.77 & -6.07 & -0.36 & 0.21 & 0.73 & 0.43 & -0.15 \\
\hline U1 & 0.45 & -1.73 & -6.18 & -0.55 & 5.36 & -0.45 & -4.22 & 0.21 \\
\hline U2 & -0.53 & 7.47 & 11.23 & 0.48 & -15.14 & 0.25 & 4.42 & -0.26 \\
\hline U3 & 0.09 & -4.42 & -4.35 & -0.57 & 2.57 & -0.36 & -4.78 & 0.42 \\
\hline U4 & -0.06 & 1.44 & -7.73 & -0.28 & 15.54 & -0.37 & 0.15 & 0.14 \\
\hline U5 & 0.18 & -4.15 & -3.99 & -1.18 & 11.94 & 0.05 & 0.53 & 0.09 \\
\hline U6 & -0.14 & -0.66 & 3.73 & -0.57 & -7.75 & -0.14 & -2.70 & 0.03 \\
\hline U7 & -0.18 & 0.81 & 7.20 & 1.02 & -9.20 & -0.52 & 0.39 & -0.11 \\
\hline U8 & 0.12 & 0.16 & -1.50 & -0.07 & 2.38 & 0.42 & 1.31 & 0.1 \\
\hline U9 & -0.08 & -0.48 & 3.41 & 1.11 & -1.38 & 0.22 & 0.79 & 0.04 \\
\hline$p=*$ & 0.72 & 0.76 & 0.81 & 0.57 & 0.61 & 0.13 & 0.32 & 0.11 \\
\hline High** & 0.45 & 7.47 & 11.23 & 1.11 & 15.54 & 0.73 & 4.42 & 0.42 \\
\hline
\end{tabular}

were calculated. The residual values for these elements at each grid position, together with the highest value for each element are shown in Table IV. The students $t$-test shows no differences between the $\mathrm{L}$ and $\mathrm{U}$ groups.

\section{Samples from Near Pipelines}

\section{Huntsman Tioxide}

Fine fraction There were considerable differences in the appearance of filtered fines between stations. Stations T8, 16, 17, 18, 19, 26, 27 and 28 had a rust-red tinge while fines from other stations were generally grey/pale-orange in colour. Red fines were particularly rich in Fe with many also rich in Ti. The samples appeared as a 'crust' of fine, particulate material within which were embedded small sand grains. Particles rich in Ti were embedded in the matrix of some samples. Of the 19 elements sought by EDX, only $\mathrm{Mg}, \mathrm{Al}, \mathrm{Si}, \mathrm{K}, \mathrm{Ca}, \mathrm{Ti}, \mathrm{Fe}$ and $\mathrm{P}$ were present in significant amounts in at least three of the five analyses per sample from each station. The amounts of signature elements $\mathrm{Ti}$ and $\mathrm{Fe}$, expressed as a weight percent (wt.\%), at each station together with the composite means and standard deviations of the means $(S D)$, maximum and minimum values are shown in Table V.

Coarse fraction The morphological appearance of the coarse fraction varied considerably between samples from quite small $(0.3-1 \mathrm{~mm})$, uniform particles at positions 12 , 16, 19 and $28-32$ to large $(0.5-3 \mathrm{~mm})$, very irregular gravel at most other stations. Large shell fragments were present at position 37. The elemental composition of most sands fell within the normal range. Particularly high wt. $\%$ of marker element Ti was noted at stations 27 and 28. Fe was particularly high at station 28. Si was high in most stations and $\mathrm{Ca}$ low in many. The amounts of signature elements, expressed as wt. \% at each station, together with the composite means, $S D$, maximum and minimum values are shown in Table V. Individual sand grains were examined at grid positions where a high wt.\% of Ti was noted. X-ray maps showed an encrustation of $\mathrm{Ti}$ and $\mathrm{Fe}$ on the surface of some grains (Fig. 3). 
TABLE V The wt. \% of signature elements ( $\mathrm{Ti}$ and $\mathrm{Fe}$ ) in the fine and coarse fraction of sediments from near the Huntsman Tioxide outfall. Also shown are the excess concentrations, the mean, $S D$, high and low values for each set of data

\begin{tabular}{|c|c|c|c|c|c|c|}
\hline \multirow[t]{2}{*}{ Grid } & \multicolumn{2}{|c|}{ Fines } & \multicolumn{2}{|c|}{ Coarse } & \multicolumn{2}{|c|}{ Excess Concentration } \\
\hline & $T i-K$ & $\mathrm{Fe}-\mathrm{K}$ & $T i-K$ & $\mathrm{Fe}-\mathrm{K}$ & $T i-K$ & $\mathrm{Fe}-\mathrm{K}$ \\
\hline $\mathrm{T} 1$ & 2.2 & 16.7 & 0.4 & 3.5 & 0.79 & -3.70 \\
\hline $\mathrm{T} 2$ & 2.2 & 16.6 & 0.2 & 1.8 & 0.99 & 2.05 \\
\hline $\mathrm{T} 3$ & 1.8 & 16.8 & 0.4 & 1.5 & 0.39 & 3.29 \\
\hline $\mathrm{T} 5$ & 2.7 & 20.5 & 0.2 & 1.8 & 1.49 & 5.95 \\
\hline T6 & 6.7 & 21.7 & 0.8 & 2.6 & 4.88 & 4.40 \\
\hline $\mathrm{T} 7$ & 2.7 & 23.9 & 0.5 & 3.3 & 1.19 & 4.19 \\
\hline T8 & 3.3 & 29.8 & 0.3 & 1.5 & 1.99 & 16.29 \\
\hline $\mathrm{T} 10$ & 2.3 & 20.6 & 1.1 & 3.8 & 0.18 & -0.83 \\
\hline $\mathrm{T} 12$ & 2 & 14 & 0.3 & 1.3 & 0.69 & 1.18 \\
\hline $\mathrm{T} 13$ & 1.8 & 15.3 & 0.2 & 1.3 & 0.59 & 2.48 \\
\hline $\mathrm{T} 14$ & 2 & 19.3 & 0.4 & 1.9 & 0.59 & 4.41 \\
\hline $\mathrm{T} 15$ & 2.5 & 26.3 & 0.3 & 2.1 & 1.19 & 10.72 \\
\hline T16 & 5.5 & 42.1 & 0.5 & 4.6 & 3.99 & 17.91 \\
\hline T17 & 11.3 & 32.7 & 0.7 & 1.7 & 9.59 & 18.50 \\
\hline T18 & 5 & 33.8 & 0.4 & 1.6 & 3.59 & 19.94 \\
\hline T19 & 4.7 & 33.9 & 0.7 & 3.2 & 2.99 & 14.53 \\
\hline $\mathrm{T} 21$ & 1.6 & 16 & 0.1 & 0.8 & 0.49 & 4.90 \\
\hline $\mathrm{T} 22$ & 1.6 & 15.7 & 0.2 & 1.4 & 0.39 & 2.53 \\
\hline $\mathrm{T} 23$ & 1.5 & 17.1 & 0.2 & 1 & 0.29 & 5.31 \\
\hline $\mathrm{T} 24$ & 1.9 & 20.4 & 0.6 & 4 & 0.29 & -1.72 \\
\hline $\mathrm{T} 25$ & 2.3 & 21.1 & 0.3 & 1.4 & 0.99 & 7.93 \\
\hline T26 & 11.4 & 29 & 0.3 & 1.8 & 10.09 & 14.45 \\
\hline $\mathrm{T} 27$ & 12.2 & 31.8 & 1.7 & 2 & 9.48 & 16.56 \\
\hline T28 & 10.2 & 36.8 & 1.7 & 5.8 & 7.48 & 8.48 \\
\hline T29 & 2.2 & 18.4 & 0.2 & 1.4 & 0.99 & 5.23 \\
\hline T30 & 3.3 & 19.4 & 0.3 & 1 & 1.99 & 7.61 \\
\hline T31 & 3.9 & 22.1 & 0.4 & 3.5 & 2.49 & 1.70 \\
\hline T32 & 2.6 & 18.9 & 0.1 & 2.5 & 1.49 & 1.94 \\
\hline $\mathrm{T} 33$ & 3 & 20.3 & 0.5 & 2.2 & 1.49 & 4.38 \\
\hline T34 & 1.6 & 14.6 & 0.5 & 2 & 0.09 & -0.64 \\
\hline T35 & 1.7 & 13.3 & 0.7 & 2.2 & -0.01 & -2.62 \\
\hline T37 & 1.5 & 14 & 0.1 & 1.4 & 0.39 & 0.83 \\
\hline T38 & 2.4 & 17.2 & 0.2 & 2.2 & 1.19 & 1.28 \\
\hline T39 & 4.9 & 22.5 & 0.5 & 2.3 & 3.39 & 6.23 \\
\hline $\mathrm{T} 40$ & 2 & 16.4 & 0.3 & 2.3 & 0.69 & 0.13 \\
\hline Mean & 3.7 & 22 & 0.5 & 2.2 & 2.25 & 5.88 \\
\hline$S D$ & 3 & 7.4 & 0.4 & 1.1 & 2.80 & 6.44 \\
\hline High & 12.2 & 42.1 & 1.7 & 5.8 & -0.01 & -3.70 \\
\hline Low & 1.5 & 13.3 & 0.1 & 0.8 & 10.09 & 19.94 \\
\hline \multicolumn{5}{|c|}{ Control Maxima } & 0.73 & 4.42 \\
\hline
\end{tabular}

\section{RICHARDS BAY}

Fine Fraction There was little difference in either the colour or morphological appearance of filtered fines from the various grid positions. All samples were off-white to pale grey/brown in colour and each was composed of small irregular particles. Positions E3, D3 and D6 were particularly pale, and rich in Ca and P. Of the 19 elements sought by EDX, only $\mathrm{Mg}, \mathrm{Al}, \mathrm{Si}, \mathrm{K}, \mathrm{Ca}, \mathrm{Fe}$ and $\mathrm{P}$ were present in significant amounts in at least three of the five analyses per sample from each grid composition. The amounts of signature element ( $\mathrm{Ca}$ and $\mathrm{P}$ ), expressed as a weight percent, at each grid position together with the composite means, $S D$, maximum and minimum values are shown in Table VI. 


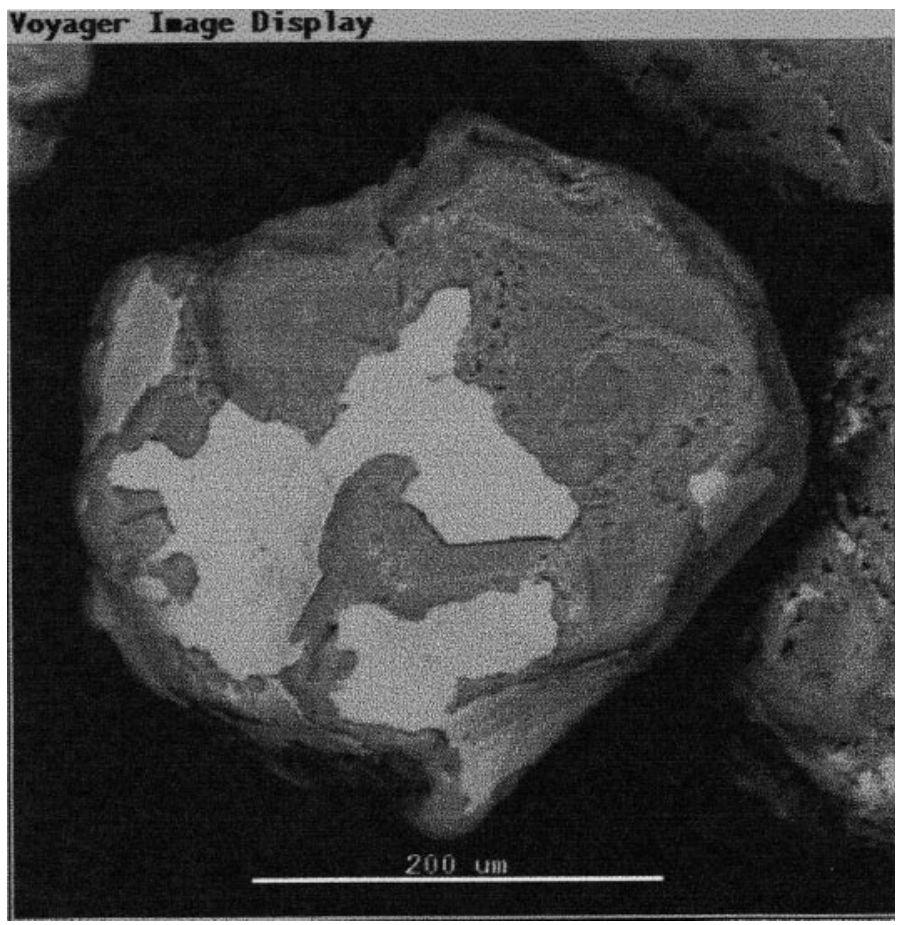

FIGURE 3 SEM image of sand grain showing pale Fe and Ti rich 'amalgam' on surface. The grain is from position 27 near the Huntsman Tioxide pipeline.

Coarse Fraction The coarse fraction from each position contained irregularly shaped sand grains ranging in size from 0.3 to $1.5 \mathrm{~mm}$. Position E3 was composed of normal sand grains interspersed with flakes of similar size, shape and elemental composition to those observed in pipeline $\mathrm{B}$ effluent. This position was rich in $\mathrm{Ca}$ and $\mathrm{P}$. Position D5 had a higher than normal amount of Fe and D5 marginally higher amounts of $\mathrm{Mg}$ and Ti. All other element wt. \% were within normal values. The amounts of signature elements at each grid position together with the composite means, $S D$, maximum and minimum values are shown in Table VI.

\section{Excess Concentrations}

The data from pristine areas showed that although there were substantial variations in the elemental compositions of sediments from different locations, the amounts of elements in the coarse and fine fractions of particular samples correlated with each other. It was postulated that the particulate/flocculant fall-out from industrial effluent would preferentially intersperse with the fine fraction, thereby causing a disturbance in the normal correlation of elements in the two size-fractions. From this it was considered probable that measurement of these disturbances would be a more sensitive indicator of the presence and amount of fall-out on the sea-bed than measurement of the coarse or fine fractions individually.

The measure chosen to represent this disturbance was the difference between the measured wt.\% of an element in the fine fraction and its expected value, based 
TABLE VI The wt.\% of signature elements ( $\mathrm{Ca}$ and $\mathrm{P})$ in the fine and coarse fraction of sediments from near the Richards Bay A and B lines. Also shown are the excess concentrations, the mean, $S D$, high and low values for each set of data

\begin{tabular}{|c|c|c|c|c|c|c|}
\hline \multirow[t]{2}{*}{ Grid } & \multicolumn{2}{|c|}{ Fines } & \multicolumn{2}{|c|}{ Coarse } & \multicolumn{2}{|c|}{ Excess concentration } \\
\hline & $\mathrm{Ca}-\mathrm{K}$ & $P-K$ & $\mathrm{Ca}-\mathrm{K}$ & $P-K$ & $C a-K$ & $P-K$ \\
\hline E2 & 40.1 & 10.5 & 16 & 1.7 & 34.45 & 10.02 \\
\hline E3 & 67.2 & 21.3 & 19.8 & 13.7 & 59.71 & 20.82 \\
\hline E4 & 25.6 & 5.1 & 10.5 & 1.7 & 22.21 & 4.62 \\
\hline E5 & 7.9 & 1.4 & 13.8 & 0.5 & 3.20 & 0.92 \\
\hline E7 & 7.5 & 0.4 & 10.7 & 0.7 & 4.04 & -0.08 \\
\hline D2 & 13.7 & 3.5 & 15.8 & 3.4 & 8.14 & 3.02 \\
\hline D3 & 52.9 & 16.9 & 9 & 2.3 & 50.06 & 16.42 \\
\hline D4 & 29.5 & 4.3 & 11 & 0.8 & 25.92 & 3.82 \\
\hline D5 & 10.7 & 1.7 & 11.3 & 0.6 & 7.01 & 1.22 \\
\hline D6 & 44.5 & 13.6 & 9.2 & 2.9 & 41.59 & 13.12 \\
\hline D7 & 14 & 0.7 & 11.6 & 0.5 & 10.19 & 0.22 \\
\hline Mean & 28.5 & 7.2 & 12.6 & 2.6 & 24.23 & 6.74 \\
\hline$S D$ & 20.3 & 7.2 & 3.4 & 3.8 & 19.85 & 7.24 \\
\hline High & 67.2 & 21.3 & 19.8 & 13.7 & 59.71 & 20.82 \\
\hline Low & 7.5 & 0.4 & 9 & 0.5 & 3.20 & -0.08 \\
\hline \multicolumn{5}{|c|}{ Control Maxima } & 15.54 & 0.42 \\
\hline
\end{tabular}

on the measured wt. $\%$ in the coarse fraction, and the correlation established from the pristine control areas. This is illustrated in Fig. 4. The points represent $\mathrm{Fe}$ measurements in the coarse and fine fractions of samples obtained from the sea-bed in the vicinity of the Huntsman Tioxide pipeline, whereas the lines represent the relationship derived from the uncontaminated control areas. The thick solid line shows the mean (expected) relationship, while the thinner lines show the maximum (C) and minimum deviations from the mean relationship encountered in the control areas. It can be inferred that the points that fall between these limits come from locations that have probably not been significantly affected by fallout from the pipeline. Subtracting the mean line from the points gives the best estimate of the contribution to the level of $\mathrm{Fe}$ in the corresponding samples which originated from the pipeline. This is illustrated in Fig. 4 for the point at A, where the distance AB was taken as representing the degree of $\mathrm{Fe}$ contamination at that location. The same subtraction procedure was applied to all the measurements of $\mathrm{Fe}$, and after plotting against the appropriate control regression, for $\mathrm{Ti}, \mathrm{Ca}$ and $\mathrm{P}$. For brevity, the quantities determined in this way will be referred to hereafter as the excess concentrations (EC) of the respective elements. Contour plots of EC were prepared using Surfer 16 software. The upper line in Fig. 4 represents the lower limit at which the presence of Fe from the pipeline can be inferred with confidence (the value corresponding to the distance BC in Fig. 4), and is the first contour in Fig. 5. This rationale was observed for the first contour line for Ti, $\mathrm{Ca}$ and $\mathrm{P}$ (Figs 6-8 respectively).

Huntsman Tioxide:Excess Concentrations The $\mathrm{EC}$ of $\mathrm{Ti}$ and $\mathrm{Fe}$ at each station together with the composite means, $S D$, maximum and minimum values are shown in Table $\mathrm{V}$ and presented as contour maps in Figs 5 and 6 . Titanium was generally dispersed in an easterly direction with a 'plateau' of deposition at stations 7, 19, 39, 25, and 5. The primary sites of Ti deposition ('hot-spot') were stations 17, 


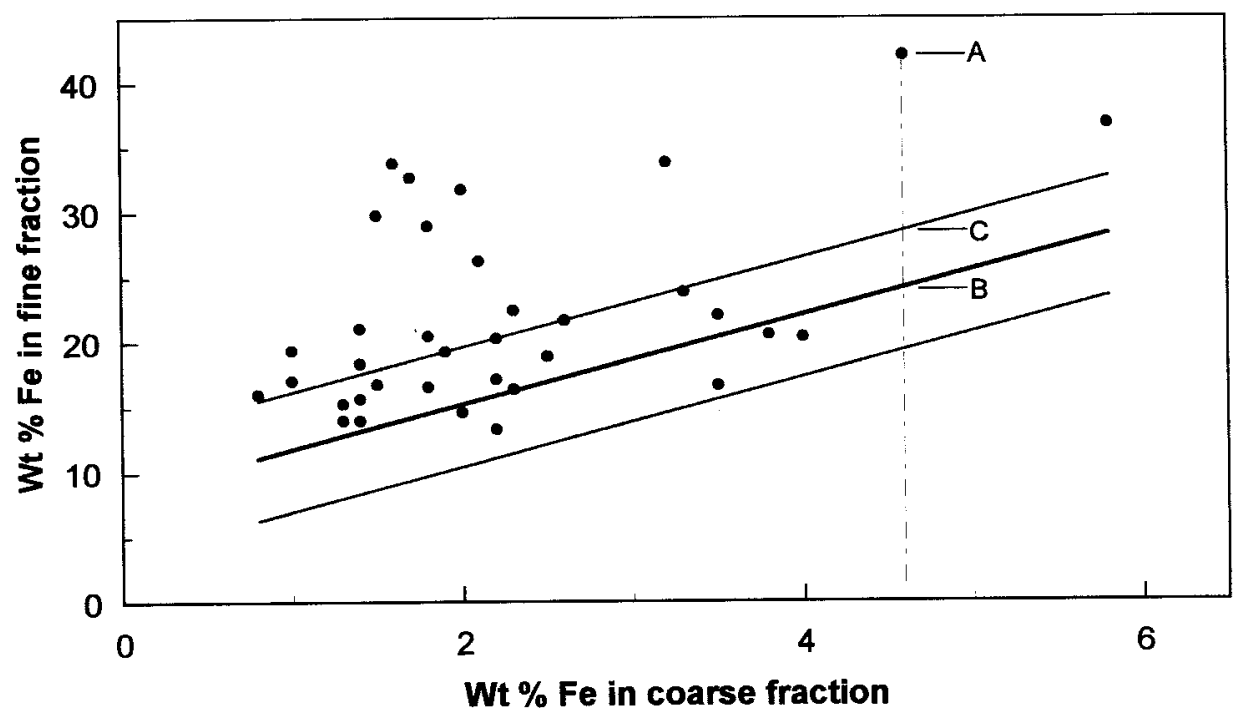

FIGURE 4 Fe-K data for the coarse and fine fractions of samples taken from the vicinity of the Huntsman Tioxide pipeline. The lines represent the corresponding data for the uncontaminated control areas. The thick solid line shows the mean relationship found between Fe concentrations in the two size fractions while the two thinner lines show the range of deviations from the mean line. The construction shown for data point $\mathrm{A}$ is a graphical illustration of the procedure for determining the excess Fe concentration.

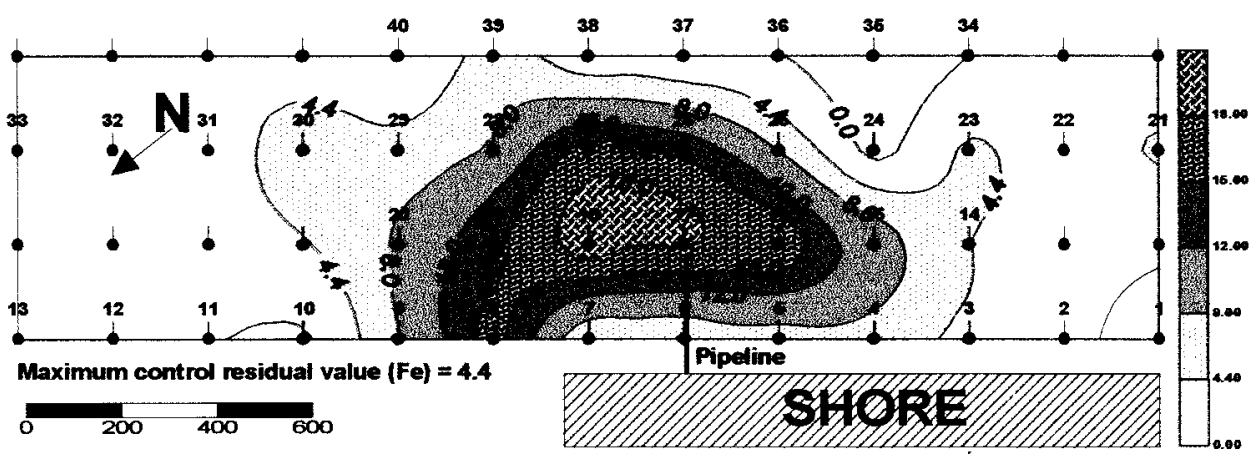

FIGURE 5 Contour map showing the distribution of excess concentrations of $\mathrm{Fe}$ in the vicinity of the Huntsman Tioxide pipeline.

26 and 27 , up to $200 \mathrm{~m} \mathrm{E}$ of the outfall. In the case of $\mathrm{Fe}$, the area of deposition extended $600 \mathrm{~m} \mathrm{~N} / \mathrm{NE}$ and $400 \mathrm{~m} \mathrm{~W}$ of the pipeline. Hot-spots were located at positions 17 and 18 within a plateau of deposition delimited by positions 9, 20, 28, 26, 15, 5 and 7 .

Richards Bay: Excess Concentrations The $\mathrm{EC}$ of $\mathrm{Ca}$ and $\mathrm{P}$ at each grid position together with the composite means, $S D$, maximum and minimum values are shown in Table VI and presented as contour maps in Figs. 7 and 8. Particularly high values for Ca were present at E3, D3 and D6 while P was in particularly high concentrations at sites D3 and D6. With the exception of E7, D2 and D7, P was higher than normal in all other selected positions. 


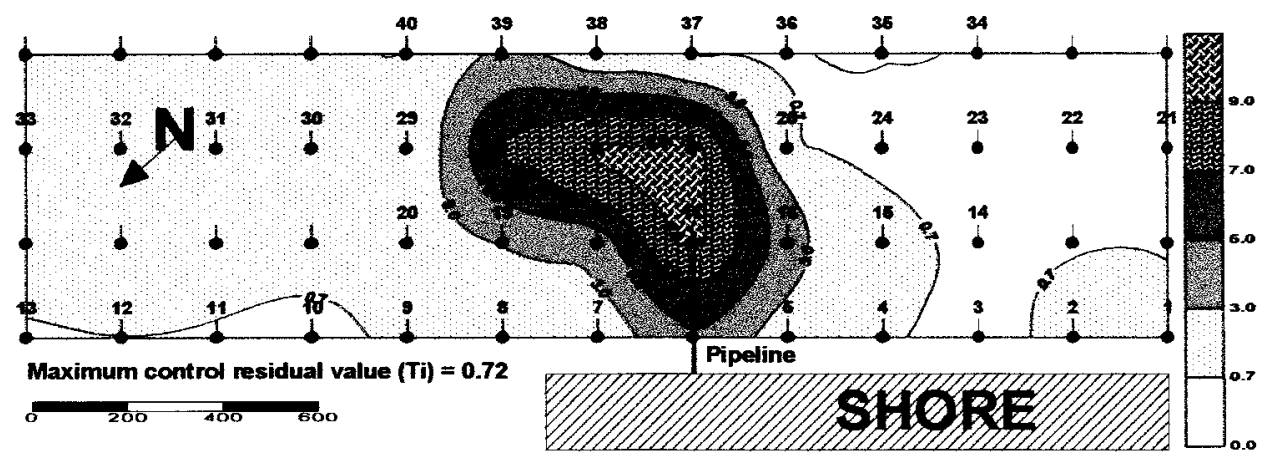

FIGURE 6 Contour map showing the distribution of excess concentrations of Ti in the vicinity of the Huntsman Tioxide Pipeline.

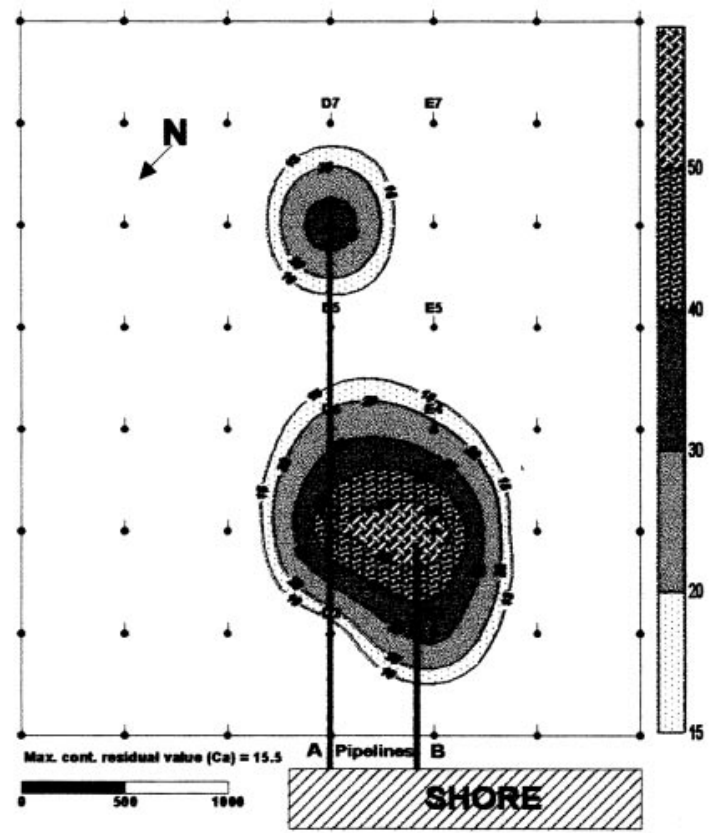

FIGURE 7 Contour map showing the distribution of excess concentrations of Ca in the vicinity of A and B pipelines at Richards Bay.

\section{DISCUSSION}

Pipeline discharges may introduce solids and flocculants into the marine environment. Such materials will eventually settle on the sea-bed and merge with existing sediments where they may serve as 'tracers' to delimit an area influenced by an outfall [13]. Tracer substances/elements have been divided into two categories: active and passive. Active tracers are substances added to an effluent that can subsequently provide a measure 


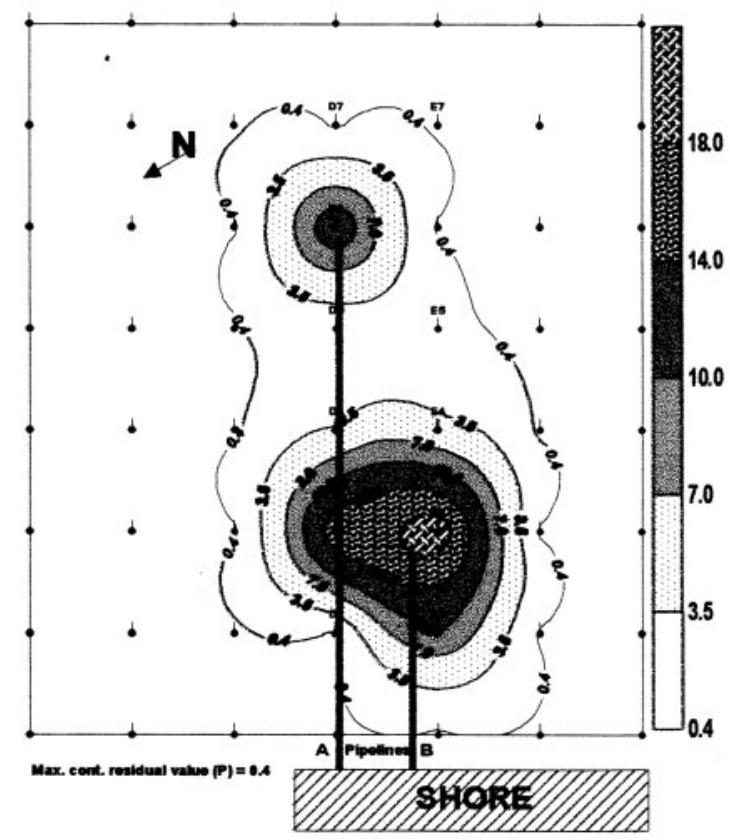

FIGURE 8 Contour map showing the distribution of excess concentrations of $\mathrm{P}$ in the vicinity of $\mathrm{A}$ and $\mathrm{B}$ pipelines at Richards Bay.

of the movement and distribution of the material in the marine environment. Such substances include radioactive isotopes [14], magnetic and rare-earth markers such as Ta and Co [15] and bacterial tracers [16]. Passive tracers are materials/substances already present in the effluent as they leave the factory or treatment works. In the case of 'sludges' from sewage works, tomato [17] and melon seeds [18], synthetic organic compounds such as PCBs and pesticides [19] and a variety of naturally occurring microbial agents [20] have been used to map effluent fall-out. Trace metals have been widely used as tracers for industrial waste [1,2]. To date, while EDX has been used to determine the speciation of marine suspended particles [21], monitor the translocation and mixing of fill sands [22] and describe the source and intermixing of sea-floor sediments [23], the methodology does not appear to have been used to monitor the dispersal of fall-out from effluent on the sea-bed.

Sediments obtained from the sea-bed can be separated into coarse and fine fractions. The coarse fraction is largely composed of sands, gravels and calcerous, biogenic materials while fines are composed of particulate material, eroded by tide and current from the coarse fraction, and the remnants of faunal and floral decomposition and marine detritus that settle on the sea-bed [24]. When trying to determine the extent of contamination due to an industrial source, the natural variation in the elemental composition of sediments from different locations is a complicating factor, which could prevent the accurate location and quantification of elements derived from effluent. This would especially be the case if signature elements in effluent were similar to those naturally occurring in both the coarse and fine fractions of sediments at sampling sites influenced by an outfall. However, the existence of an intrinsic relationship between the elemental composition of the different sized fractions in sediments from 
pristine areas suggested a way of compensating for natural variations in the composition of disparate sediments - especially as material from an industrial source is unlikely to follow the natural relationships. In particular, the industrial material is likely to be predominantly fine, due to chemical processing. Hence the composition of the fine fraction would probably be more strongly affected by effluent than the coarse fraction. If this were so, contamination should be readily detected by an increase in the wt. $\%$ of a signature element in the fine fraction, relative to the value calculated from the coarse fraction value using the natural relationship. This was found to be the case when monitoring the deposition of signature elements from the three pipelines.

Huntsman Tioxide The high concentration of $\mathrm{Ti}$ in particulate material in this effluent rendered it a useful 'tracer' or 'signature' element. The primary sites of Ti deposition ('hot-spots') were within $200 \mathrm{~m}$ NE of the outfall. The primary 'plateau' of deposition was also to the north east. The large amount of Fe on the sea-bed in the vicinity of the outfall was initially unexpected, for no particulate Fe was detected in the effluent and only relatively small amounts were found in the aqueous fraction. However, in the $\mathrm{TiO}_{2}$ refining process iron is removed as Fe II in solution. When the effluent reaches the sea, the dissolved $\mathrm{O}_{2}$ in sea-water converts the soluble Fe II into insoluble Fe III, which precipitates around the outfall as the hydrated hydroxide. The flocculated Fe III hydroxide is less dense than the particulate $\mathrm{TiO}_{2}$, and is therefore dispersed more widely about the outfall. 'Hot-spots' were located around stations 17 and 18. The area of deposition extended $600 \mathrm{~m} \mathrm{~N} / \mathrm{NE}$ and $400 \mathrm{~m} \mathrm{~W}$ of the pipeline.

Of particular interest were the large amounts of $\mathrm{Ti}$ and $\mathrm{Fe}$ in the washed, coarse fraction of some sediments. As sediments in the region of the outfall were not expected to be particularly rich in either element, we investigated this anomaly further. Spot EDX analyses revealed individual sand grains rich in these two elements. X-ray mapping showed that Fe and Ti were present as an 'amalgam' on the surface of each particle (Fig. 3). Further investigation suggested that these grains were probably formed in the initial extraction process, and were residues from the acid dissolution of the Ti- and Ferich slag which is the first step of the refining process. These grains, therefore, where not a natural constituent of the local sediments, but had been discharged with the effluent from the plant.

Richards Bay The effluent discharged from the B-Line is a gypsum slurry from a phosphoric acid plant and is therefore rich in particles of $\mathrm{Ca}$ and $\mathrm{P}$. This was reflected in the amount of $\mathrm{Ca}$ and $\mathrm{P}$ in the fine fraction of sediments near each outfall. The amount of $\mathrm{Ca}$ was four times, and $\mathrm{P} 50$ times higher at position E3 near and the end of B-Line than maximal values for the same elements in sediments from remote areas on this grid and pristine areas [7]. Near the end of the A-Line (D4), Ca was only twice and P, 31 times higher. Positions E5 and D5 were almost equidistant from each outfall and they showed minimal increases above normal for both elements. This showed that even with a small number of sample sites, the Surfer software enabled the location and mapping of elements in discrete areas about their respective outfalls.

The use of a passive tracer requires particular care in compensating for background levels in the natural marine sediments. As shown in this study, the background levels can vary substantially from one location to another. The use of excess concentrations in the fine fraction of the sediment, as defined in this paper, helped to overcome the problem. It should be noted, however, that the particular methodology used here may 
not be the most appropriate in every case. It was based on the assumption that the foreign material originating from the pipeline would contribute predominantly to the fine fraction of material, so that the natural contribution to the measured level of tracer element in the fine fraction could be inferred from the coarse fraction. The Fe and $\mathrm{Ti}$ rich coarse particles found near the Huntsman Tioxide pipeline show that this will not always be true - even though in this case the contaminated particles were almost certainly derived from the factory. However, it can be expected that coarse contaminants would settle very rapidly, and so be found only very close to the outlet of the pipeline.

The usual approach in marine pollution, monitoring surveys is to measure element concentrations in sediments using AA. This methodology can be time consuming and expensive. While EDX methodology lacks the sensitivity of AA to detect heavy metals in trace amounts $(\mathrm{ppm})$, our results show that it can detect and determine the relative amounts of particulate and flocculant signature elements in effluent that deposit on the sea-bed. The methods described here are relatively quick, cheap and simple to perform. Further, the areas deliminated by EDX generally conform to the areas delineated by the AA of raw sediments for heavy metals from the same pipelines [1,2]. It is suggested, therefore, that EDX could be used as a preliminary means of identifying areas of high deposition (hot-spots) and delimiting an area influenced by fall-out from an outfall. Thereafter, more sensitive techniques (AA) could be focussed on areas demarcated by EDX.

In conclusion, this pilot study details methodology for the preparation of samples of sediment for EDX. It also shows an apparent 'natural' inter-relationship between the coarse and fine fractions of sediments in disparate pristine sites irrespective of their elemental composition. Adjusting data to accommodate for this relationship reduces positional disparity and establishes a baseline against which to identify and quantify the amount of signature elements from fall-out deposited in sea-bed sediments. The results confirm that data obtained by EDX from sediments prepared in the manner described above, can be employed to demarcate areas influenced by outfalls and identify 'hot-spots' rich in signature elements. The method appears to offer a simple and rapid means to screen sediments and identify 'hot-spots' on the sea-bed. These 'hot-spots' can then be subjected to a more focussed analysis using methods such as atomic absorption spectrometry which allow accurate quantification. It is suggested that EDX could be employed as a preliminary line of investigation in pollution impact studies.

\section{Acknowledgements}

The authors would like to thank Dr. Allan Connel of the CSIR for his constructive comments. We would also like to thank Hunstman Tioxide and the Mhlathaze Water Board for the use of their samples. This study was supported by the National Research Foundation (NRF) of South Africa.

\section{References}

[1] CSIR (2001a). Environmental Studies in the RichardsBay Offshore Outfall Region. Report No. 14. Surveys made during 2000. Division of Water, Environment and Forestry Technology; CSIR Durban, CSIR Report ENV-D-C-2001-015. 
[2] CSIR (2001b). Sea Dispersal of Sewage: Environmental Survey in the Durban Outfalls Region. Report No. 19. Surveys Made During 2000. Division of Water, Environment and Forestry Technology; CSIR Durban, CSIR Report ENV-D-C-2001-004.

[3] A. Tessier, P.G.C. Campbell and M. Bisson (1979). Anal. Chem., 51, 844-851.

[4] P.P. Coetzee (1993). Water SA, 19, 291-300.

[5] P.P. Coetzee, K. Gouws, S. Pludderman, M. Yacoby, S. Howell and L. den Drijver (1995). Water SA, 21, 51-60.

[6] M. Chartier, G. Mercier and J.F. Blaise (2001). Water Res., 35(6), 1435-1444.

[7] J.S. Gray (1981). The Ecology of Marine Sediments. An Introduction to the Structure and Functioning of Benthic Communities, Cambridge University Press, Cambridge.

[8] R.B. Clark (1989). Marine Pollution. Oxford University Press, New York.

[9] J.G. Field, K.R. Clarke and R.M. Warwick (1982). Marine Ecology Progress Series, 8, 37-52.

[10] K.J. Farley (1990). J. Environ. Eng., 116(1), 144-165.

[11] G.J.M. Copeland (1992). Water Sci. and Technol., 25(9), 189-195.

[12] A.S. Arcilla, A. Rodriguez and M. Mestres (1998). J. Mar. Environ. Eng., 4, 217-243.

[13] C.M.G. Vivian (1986). Sci. Total Environ., 53, 5- 40.

[14] G. Courtois (1967). Radioisotopes in Sedimentology, pp. 117-165. International Atomic Energy Agency, Vienna.

[15] R. Maxted (1984). Water Waste Treat, 27, 47-50.

[16] E.B. Pike, A.W.J. Bufton and D.J. Gould (1969). J. Appl. Bacteriol., 32, 206-216.

[17] R.G.R. Shelton (1971). Mar. Pollut. Bull., 2, 24-27.

[18] M.A. Champ and P.K. Park (1981). Sea Technol., 22, 18-24.

[19] D.W. Lear and M.L. O’Malley (1983). Effects of sewage sludge dumping on continental shelf benthos. In: I.W. Duedall, B.H. Ketchum, P.K. Park and D.R. Kester (Eds.), Wastes in the Ocean. Vol. 1 - Industrial and Sewage Wastes in the Ocean, pp. 293-311. Wiley, New York.

[20] G. Bitton and K.C. Marshall (1980). Adsorption of Microorganisms to Surfaces, pp. 439-451. Wiley, New York.

[21] C. Ianni, F. Baffi, M. Ravera, F. Soggia and R. Frache (1994). Proc. Congresso dell Assoziazione Italian di Oceanologia e Limnolgia. Sorrento., 15, 551-561.

[22] J. Kropp, A. Block, W. Von Bloh, T. Klenke and H.J. Schellnhuber (1997). Sed. Geol., 109(1), 37-51.

[23] K. Iizasa (1993). Mar. Geol., 112, 1-4, 271-290.

[24] A.P. Lisitzin (1996). Oceanic Sedimentation - Lithology and Sedimentation. American Geophysical Union, Washington, pp. 47-73. 
Copyright $\odot 2003$ EBSCO Publishing 